\title{
Overview of power quality analysis and control technology for the smart grid
}

\author{
An LUO ${ }^{1}$, Qianming XU ${ }^{1}$, Fujun MA ${ }^{1}$, Yandong CHEN ${ }^{1}$
}

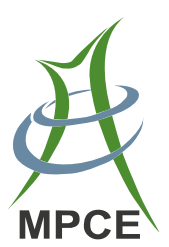

\begin{abstract}
With the wide application of non-linear loads and the large-scale access of distributed energy generations based on power electronics equipments, power quality problems in the distribution network are increasingly serious with new characteristics. Further in-depth research is of great significance in theory and practice. This paper provides an overview of power quality analysis, compensators, and control technologies under the new situation of smart grid. It focuses on the topologies and control methods for power quality conditioners, especially new characteristics of power quality and applicable control technologies in microgrids and distributed power plants. Finally, trends and prospects of power quality control technology are introduced, which is important to achieve security and efficient operation of the smart grid.
\end{abstract}

Keywords Power quality, Smart grid, Active control, Passive control

CrossCheck date: 14 November 2015

Received: 14 November 2015/Accepted: 28 December 2015/ Published online: 19 January 2016

(C) The Author(s) 2016. This article is published with open access at Springerlink.com

$\triangle$ An LUO

an_luo@126.com

Qianming XU

hnuxqm@foxmail.com

Fujun MA

mafujun2004@163.com

Yandong CHEN

xlcyd520@163.com

1 National Electric Power Conversion and Control Engineering Technology Research Center (Hunan University), Changsha, China

\section{Introduction}

In the modern smart grid, the diversity of loads and the demands for highly efficient consumption, as well as the use of renewable energy (solar, wind, biomass energy, etc.) generation and grid connection technology through the power electronics interfaces, have brought great challenges to governing power quality [1-4]. Compared with the traditional power system, the microgrid or distributed power plant, which integrates a variety of energy inputs, multiple load characteristics, and varied energy conversion technologies, is a nonlinear and complex system with intercoupling of chemical energy, thermodynamics and electrodynamics. Meanwhile, due to the limitation of natural resources, the distributed generations (DGs) appear the features of intermittency, complexity, diversity and instability. Accordingly, some new problems with novel features occur in maintaining power quality. Therefore, power quality control theory and technology will play an important role in ensuring the stable and secure operation of the power grid when microgrids or distributed power plants are connected to it. In the Chinese national program for longand medium-term scientific and technological development (2006-2020), it is specifically mentioned that the analysis, detection, and control technology for power quality should be a priority objective in the energy field, and it is highly recommended to promote the application of high-power power electronics technology and to control the power quality actively.

Figure 1 illustrates the typical structure of the smart grid including power quality controls. It consists of power transmission part, power distribution part, and power consumption part. The transmission grid is responsible for the regional power electricity supply and large renewable energy generation absorption. Its primary objective is to 


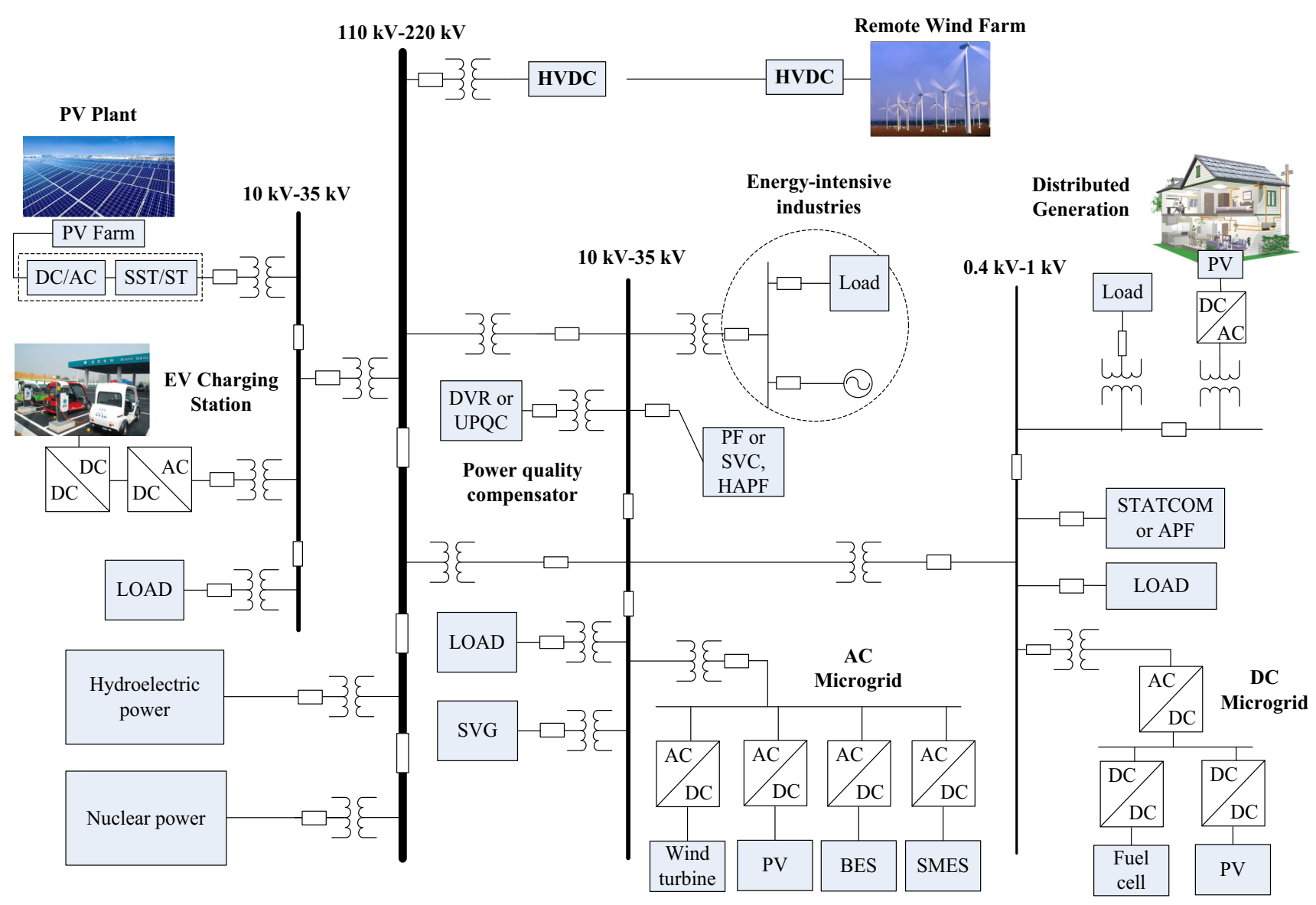

Fig. 1 Structure diagram of a typical distribution grid system containing microgrid

maintain the voltage stability of transmission lines by regulating appropriate reactive power provided by high voltage power quality compensators. The high- and medium-voltage distribution network works as the bridge that connects the transmission grid and power consumers. With the connection of large amounts of distributed energy, its power quality features appear high penetration and stochastic volatility. In consequence, multiple compensation devices are recommended to operate cooperatively for ensuring a friendly power quality. Power quality on the consumer side directly affects the power efficiency and production safety, which makes the power quality problems more complex. As a result, active control and local compensation technology are two important means to suppress the circulating current or harmonic resonance, and to analyze the emission features between DGs and electrical loads in the distribution network.

This paper provides an overview of the power quality control technology in the smart grid. Power quality compensators and their classification based on power electronics technology are comprehensively introduced. A brief description is introduced for novel power quality compensators featuring modular multilevel technology, such as solid-state transformers and high voltage DC converters. Then, the control methods of power quality compensators are discussed for high efficiency operation. Special attention is paid to the new characteristics of power quality and control technology in the distribution system with DGs. Finally, the paper analyzes the trends and prospects of power quality control technology.

\section{Power quality compensators classification}

It is important to improve the power supply quality on power consumer side by taking advantage of the power quality control technology and equipment. The core principle of power quality control is to control and convert the electric energy, so as to meet the requirement of quality conformance and optimal efficiency. The key elements to accomplish above-mentioned control and conversion are diverse power electronics devices and associated control circuits. The classification of compensators in terms of different kinds of power quality problems is depicted in Fig. 2. Power quality control technology can be divided into active control technology and passive control technology. 


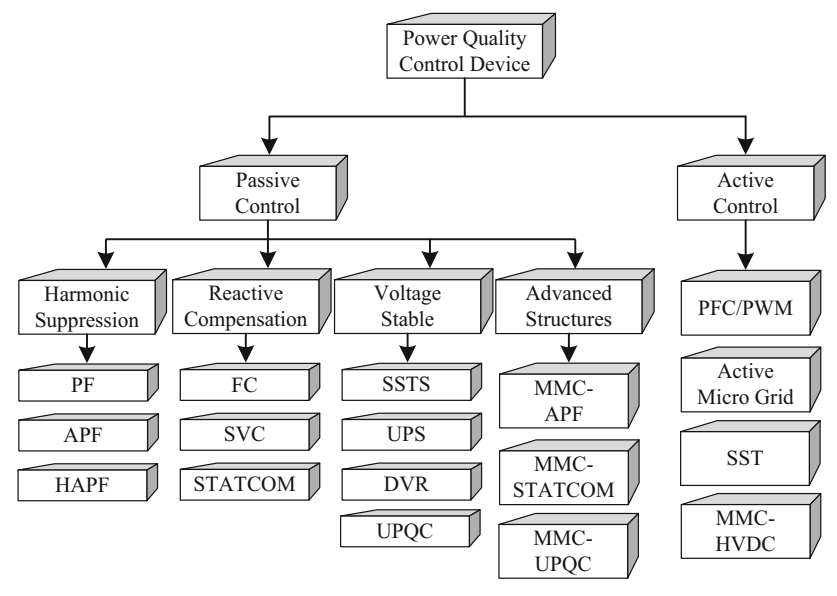

Fig. 2 Classification diagram of power quality compensators

\subsection{Passive control technology}

The passive control technology is characterized by adding extra devices to eliminate or relieve the impact of existing power quality problems. At present, the harmonic suppression techniques mainly contain the passive power filter (PPF) [5], active power filter (APF) [6, 7], and hybrid active power filter (HAPF) [8]. As mentioned in [9], HAPF can be classified as single-resonance injection hybrid active power filter (S-IHAPF), double-resonance injection hybrid active power filter (D-IHAPF), and multi-branch injection hybrid active power filter (M-IHAPF). The HAPF combines the advantages of both PPF and APF, effectively reducing the rated capacity and voltage of the active part without making a compromise of satisfactory performance in the integral filter system. It has been an effective way to suppress harmonic currents and compensate reactive power in high voltage distribution network. The reactive power compensator is capable of suppressing the voltage fluctuation and flicker. Off-the-shelf var compensators in distribution network include fixed capacitor (FC) [1, 2], static var compensator (SVC) [10], and static synchronous compensator (STATCOM) [11], etc. Among these devices, the STATCOM is widely used for its multiple functions, such as grid voltage fluctuation suppression, and unbalanced load compensation. The tendency has been to develop modularized harmonic suppression and var compensation systems due to high stability, reliability and power density.

Among the transient power quality problems, voltage sag and short interruption are perceived as the most common and harmful forms. The solid-state transfer switch (SSTS) [12] can effectively reduce the depth and time of voltage sag. Uninterruptable power supply (UPS) [13] is the most effective tool to restrain the voltage fluctuation for low-power devices in the distribution network. The dynamic voltage regulator (DVR) [14] can directly and quickly compensate the instantaneous voltage sag and swell. The unified power quality controller (UPQC) [15], comprised of the series APF and shunt APF, can make comprehensive compensation of voltage and current for the grid.

In less than two decades, cascade power converters based on modular multilevel converter (MMC) have been widely studied in scientific researches and engineering applications. Due to the identical module structure, MMC greatly reduces the manufacturing difficulty and cost of high- and medium-voltage converters. Compared with the traditional power quality compensators, MMC based compensators have special advantages in standardization, expansibility, redundancy, fault ride-through, voltage level and filtering requirement $[16,17]$. On the one hand, the modular power quality compensator can effectively lessen the rated voltage of the power switch and energy storage element in the sub module, which allows the use of lowloss and low-cost switch devices. On the other hand, the cascaded structure directly expands the application of diversified power quality compensator in medium- and high-voltage transmission systems. Currently, the APF, STATCOM, UPQC based on MMC have been discussed at a preliminary level [18-20]. Due to their novel topology, many new problems different from traditional power converters need to be addressed. More precisely, the multilevel structure inevitably requires a complex control system since large amounts of data must be processed within a short time. This limits the engineering application and development of MMC in the field of power quality control. More intensive theoretical and practical studies should be investigated to determine how to coordinate the interior power control, modulation method, circulating current suppression, and voltage balancing with exterior voltage and current compensation requirements. Fortunately, with the development of digital processing technology, the realization of complex topology and control system will gradually become simplified.

\subsection{Active control technology}

Active control technology is used to improve the impedance characteristics of the electrical equipment so as to prevent most power quality problems.

With the transmission and distribution network being instrumented, interconnected and intelligent, power quality problems caused by the future electrical equipment, especially the power electronics converting system, will be significantly mitigated. At present, the power factor correction (PFC) and pulse width modulation (PWM) technology have improved the power quality of rectifier devices [21]. The distributed generation and microgrid 
inverter using the active control [22] not only improve the quality of output voltage and current in distributed system, but also provide some extra compensation capacity for the adjacent grid. Further on, the prospective solid-state transformer (SST) [23] will block the transmission and emission of power quality problems between the power consumer side and power distribution side. The power quality level of the entire power grid will be enhanced due to the MMC-based high voltage direct current (HVDC) transmission and multi-terminal HVDC technology [24].

\section{Control method of power quality compensator}

Nowadays, power quality control equipment generally employs the voltage source converter or current source converter. The output of converters can be regulated to control the power quality according to the voltage or current reference. The control method of the converter has a significant impact on the effect on power quality control. There are a lot of literatures describing the control methods, which are hysteresis control, dead-beat control, model predictive control, proportional integral control, proportional resonant control, repetitive control, and nonlinear robust control.

Hysteresis control (HC) is simple to realize and has a fast response speed, but its control accuracy depends on the hysteresis bandwidth and the switch frequency is unfixed $[25,26]$. Dead-beat control (DBC) is based on state equations of the converter and has a good dynamic performance with convenient parametric design, but its control performance is easily affected by circuit parameters and control delay. Compensating the control delay and adding state observation can strengthen the anti-jamming ability of the system [27-29]. Based on the finite control set of the converter, model predictive control (MPC) selects the output switch state to optimize the cost function. It features good dynamic performance, but it is also a challenge to the control system because of a large computation requirement [30-32]. However, developments in digital signal processing will contribute to the scale of application of MPC. In a synchronous reference coordinate system, proportional integral (PI) control [33, 34] has been widely used due to its tracking ability without error. Nevertheless, when applied to APF, it cannot realize zero error tracking over a broad frequency range. In order to improve the performance of alternating current control, proportional resonant (PR) control has been developed to achieve infinite gain and zero error tracking at the tuned frequency [35, 36]. Repetitive control, derived from the internal model principle, makes it possible to accurately track the periodic signal and enhance the steady-state performance [37, 38], but its dynamic response still needs to be improved.
Making use of the nonlinear characteristics of the converter, sliding mode control based on feedback linearization is proposed in [39-41], where it can improve the dynamic performance as well as the robustness of the system. In [42, 43], the artificial neural network controller and the linear quadratic Gaussian controller are designed to optimize the performance of APF.

It is noteworthy that a lot of literatures promote methods to improve the compensation performance. [44] presents a multi-PR current controller based on the circuit model, which simplifies the harmonic extraction unit. [45] describes a control method with decoupled fundamental component and harmonic component, resulting in dispensable unit for the harmonic voltage and current detection. Dividing frequency control proposed in [8] and [46] reduces the compensation error of the harmonic current's amplitude and phase, which is suitable for multi-structure active power filters.

\section{Analysis and control of power quality for large scale distributed power plants}

With the increasing penetration rate of large-scale distributed power plants by year, the cross-coupling of harmonic resonance between the distributed system and multiinverter system has become increasingly complicated. The distributed power plant generates a lot of high-frequency and broadband harmonic components [47]. Moreover, there are series and parallel resonances depending on the transmission line configuration and harmonic frequencies. In cases where the background harmonic voltage matches the transmission line parameters, there will be series resonance, resulting in serious amplification of harmonic voltage. Harmonic currents generated by distributed power plants will also result in parallel resonance, causing serious current distortion, further increasing the total harmonic content in the system. Series-parallel resonances are mainly responsible for voltage and current distortions, which disturb the efficient and stable operation of distributed power plants [48, 49]. Therefore, analyzing series and parallel resonance mechanisms of distributed power plant has become a hot topic in power system research.

The influence of transmission line distributed capacitance on harmonic series and parallel resonance is analyzed in [50]. Then, a preliminary resonance suppression method is proposed in [51]. Quantitative analyses of the resonance caused by transformer magnetizing branch, parallel capacitors and other devices are presented in [52]. In [53], the step-up transformer, the reactive power compensation device, distributed capacitance of the transmission line and loads are considered to establish the multiport passive network model. This allows the transmission mechanism of 


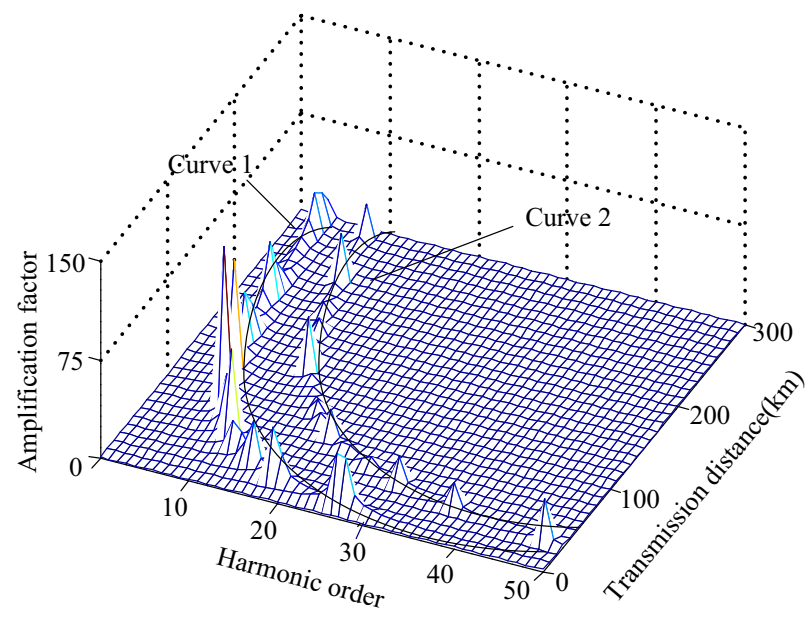

(a) Harmonic current amplification factor

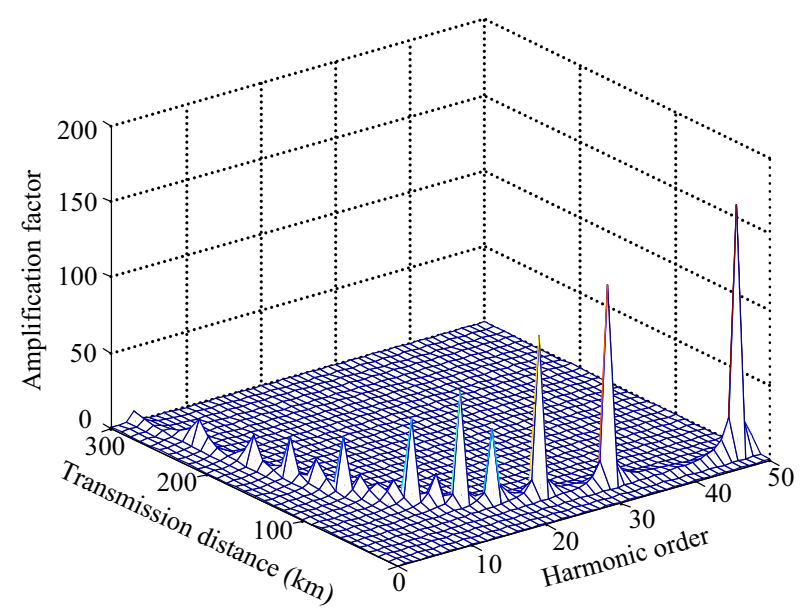

(b) Harmonic voltage amplification factor

Fig. 3 The relationship between the resonance amplification factor and harmonic order, transmission distance

harmonics to be analyzed using the definition of resonance amplification factors. As shown in Fig 3a, double resonance curves are discovered, which means that transmission lines of different distances may amplify a harmonic current twice, or a transmission line of a fixed distance may amplify the harmonic current of different frequencies. For transmission line distance within $100 \mathrm{~km}$ in resonance curve 1 , the harmonics resonance frequency is between the $11^{\text {th }}$ and $27^{\text {th }}$, and the amplification factor for the $17^{\text {th }}$ and $19^{\text {th }}$ harmonics may reach 20 . In resonance curve 2 , the dominant resonance frequency within $200-300 \mathrm{~km}$ transmission line is the $9^{\text {th }}$ harmonic, and its amplification factor can reach 10 at the resonance point. As depicted in Fig 3b, apparently, in the case of long-distance transmission $(100-300 \mathrm{~km})$, the most dominant resonance frequency is between the $5^{\text {th }}$ and $15^{\text {th }}$ harmonics; the $7^{\text {th }}$ harmonic voltage is magnified about 20 times. Whereas in the case of short-distance transmission $(0-100 \mathrm{~km})$, the dominant series resonance frequency is between the $17^{\text {th }}$ and $50^{\text {th }}$ harmonics. At the resonance points, the $17^{\text {th }}$ and $19^{\text {th }}$ harmonic voltages may magnify more than 20 times, and more than 100 times for the $23^{\text {rd }}, 27^{\text {th }}, 37^{\text {th }}$ and $49^{\text {th }}$ harmonic voltages.

Harmonics generated by large-scale distributed power plants have the characteristics of high frequency and wide frequency range. Therefore, the adverse impact of distributed parameters of high-voltage cables becomes more significant [54].

The methods to eliminate the series-parallel harmonic resonance can be summarized in two categories:

1) By changing the parameters of the transmission network, the harmonic resonance can be restrained [55]. Existing measures set the shunt reactors at both ends of transmission lines to weaken the effect of distributed capacitances. But this approach shows some drawbacks when it is applied to distributed power plants. On the one hand, the shunt reactors reduce the power factor at the export side of distributed power plants. On the other hand, the variation of the output active and reactive power of distributed power plants may cause large voltage fluctuations at the point of common coupling (PCC).

2) Adding filter device can markedly reduce the harmonic content flowing into the grid [56]. Most conventional filter devices are available for lower order harmonic currents compensation, but incapable of eliminating harmonic frequencies more than $25^{\text {th }}$. Hence, new filter topologies that can effectively accomplish broadband harmonic detection and elimination will undoubtedly be paid critical attention in the near future.

It is worthy of note that the hybrid active power filter with the grid current detection function [57] can be equivalent to a harmonic impedance in series with the grid impedance. It can ameliorate the grid equivalent impedance to suppress the resonance. Concurrently, harmonic currents will be filtered at low cost. Hence, it is useful for the harmonic management of distributed power plants.

\section{Analysis and control of power quality for microgrids and power distribution systems containing microgrids}

The DG units, energy storage system (ESS) and loads are connected to the microgrid through power electronics converters. This structure is the main form of the DGs for renewable energy at present. The power quality problems of the microgrid exist in a wide-band frequency domain along with an increasing penetration of the microgrid. 
Determining how to effectively tackle the problem of the harmonic currents in the wide-band frequency domain caused by the distributed and clustered inverters has been gained much attention in the flied of the power quality of the microgrid operating in both islanded and grid-connected mode [58]. The most significant problems in the islanded mode are how to effectively realize power sharing among parallel inverters, also reduce the fundamental and harmonic circulating currents among them. The prominent problems in grid-connected mode are how to solve the coupling resonant among parallel inverters as well as between the inverters and the distribution network. This section will focus on the new characteristics of the power quality and its control technologies in the microgrid.

\subsection{Suppression methods of internal circulating current in microgrids}

The equivalent output impedances of the parallel inverters are different from each other at PCC [59] in an $\mathrm{AC}$ or hybrid microgrid since the control strategies, filter parameters and length of transmission lines [60], are not the same. Consequently, it will cause the fundamental and harmonic circulating currents, and also the fluctuations of the amplitude and frequency of the PCC voltage of the islanded microgrid [61, 62]. There have three types of circulating currents in the islanded mode, i.e., active circulating current, reactive circulating current and harmonic circulating current. The active circulating current is caused by the frequency and phase deviations of inverter output voltages. The reactive circulating current results from the magnitude deviations of inverter output voltages. The harmonic circulating current is the result of harmonic components of inverter output voltages. The slight deviations of the frequency, phase and magnitude of the inverter output voltages will lead to large fundamental or harmonic circulating currents [63]. Moreover, the circulating currents will reduce the output capacities of the DG units, and increase the line losses, also endanger the safe operation of the microgrid $[64,65]$.

The virtual impedance technology can effectively reduce the circulating currents by changing the equivalent output impedance of the parallel inverters. The resistive (R-type) inverter, inductive (L-type) inverter, resistive-inductive (RL-type) inverter, and resistive-capacitive (RCtype) inverter can be easily designed by using the virtual impedance technology to meet the different operating requirements of the microgrid [66-69]. In general, the output impedance of the inverters in the middle-voltagelevel microgrid is designed to be inductive; on the contrary, the output impedance is often designed to be resistive-inductive in the low-voltage-level microgrid.

\subsection{Harmonic analysis and suppression in the microgrids operating in grid-connected mode}

The nonlinear action and dead time effect of distributed inverter bring plenty of high-order harmonic currents in the microgrids. Thus, the output filter devices for inverters are indispensable. There have two main types of output filter for inverters in grid-connected mode, i.e., L-type and LCLtype filter. Besides, the LC-type filter is mainly used in the islanded mode [70]. The equivalent output impedance of each inverter will easily be changed due to the deviation of filter parameters. Impedance coupling exists among the equivalent impedances of the parallel inverters, as well as between the equivalent output impedance of the inverter and the equivalent impedance of the distribution network. Therefore, it can provide a low-impedance channel for specific harmonic, resulting in the amplification of the harmonic current with specific orders. The active damping loop can provide solutions to this problem in terms of the inverter control. Cascade control method [71, 72], splitting capacitance method [73], zero-pole compensation method [74], and filter-capacitor-voltage feedback method [75] are the effective active damping schemes.

The resonant problem of multi-parallel inverters is complex [76, 77], and there exists both a fixed and an unfixed resonant band. The fixed resonant band is caused by inverter filter system, and its resonant frequencies will not migrate with the different number of parallel inverters. However, the unfixed resonant band results from the coupling effect of the equivalent output impedance of the parallel inverter system and its resonant frequencies will migrate to the low-frequency range along with the increase in the number of the parallel inverters. In addition, the series resonance exists between the parallel inverter and the distribution network [78], and its resonance peak frequency will also migrate to the low-frequency range along with the increase in the number of parallel inverters. To restrain the series resonance, the Nyquist stability criterion can be extended to provide a feasible solution for reshaping the equivalent output impedance of the inverter. Besides, the active damping schemes should be taken to attenuate the coupling resonance among parallel inverters.

\section{Trends and prospects of power quality control}

With concern about the consumption of fossil fuels and the resulting greenhouse effect, a large number of sustainable energy sources are connected to the utility grid in the form of DGs. This will affect the power quality of power grid and bring new demands of the compensation devices. At the same time, the potential application of wide 
band semiconductors ( $\mathrm{SiC}$ ), and the development of new converter topologies will promote the development of advanced power quality compensators. In addition, solid state circuit breakers, SSTS and MMC-HVDC, which can cooperatively control active power and reactive power to achieve power quality active control, have been extensively studied. The continuous application of such technology will have a positive impact on power quality control.

Considering the issues and technologies presented in these papers, the following areas require further research:

1) The harmonics generated by power electronics converters have characteristics of high-frequency, wide frequency range, and multi-type coupling. How to detect and suppress the high-order harmonics and inter-harmonics still needs to be further investigated.

2) The emission level and superposition characteristic of the power quality problem as well as the interaction effect between the micro-grid and the utility grid are worth researching.

3) Power quality characteristics of large wind power farms, photovoltaic power plants, their interaction effect with public power grid and suitable power quality control methods merit intensive research.

4) The characteristics of the power quality in large scale distributed power plant as well as the power quality control method are prime candidates for in-depth study.

5) New designs for power quality compensators based on wide band semiconductors or modular multilevel technology need to be developed.

6) The functionality and widespread application of solid state circuit breakers, solid state transformers and MMC-HVDC, all of which can perform active power quality control, require in-depth research.

\section{Conclusion}

With the growth of extensive nonlinear loads and renewable power integration, power quality problems in distribution grids have become increasingly serious. Problems such as voltage fluctuation, voltage sag, harmonic and reactive power, not only directly harm the normal operation of sensitive loads, but also decrease the power transmission efficiency of the distribution system. This paper summarizes available and emerging control technologies to solve power quality problems in the strong smart grid. Particularly, it focuses on new power quality features, control technologies and trends and prospects, to form a valuable reference to assist the secure and economical operation of distribution grids.
Acknowledgment This work was supported by the General Program of National Natural Science Foundation of China (No. 51477045).

Open Access This article is distributed under the terms of the Creative Commons Attribution 4.0 International License (http:// creativecommons.org/licenses/by/4.0/), which permits unrestricted use, distribution, and reproduction in any medium, provided you give appropriate credit to the original author(s) and the source, provide a link to the Creative Commons license, and indicate if changes were made.

\section{References}

[1] Miller TJE (1982) Reactive power control in electric system. Wiley, New York

[2] Wang ZA, Yang J, Liu JJ (2006) Harmonic suppression and reactive power compensation. Machinery Industry Press, Beijing (in Chinese)

[3] Green MA (2002) Third generation photovoltaics: comparative evaluation of advanced solar conversion options. In: Proceedings of the 29th IEEE photovoltaic specialists conference, New Orleans, 19-24 May 2002, pp 1330-1334

[4] Zhao ZM, Liu JZ, Sun XY (2005) Solar photovoltaic power generation and its application. Science Press, Beijing (in Chinese)

[5] El-Saadany EF, Salama MMA, Chikhani AY (2000) Passive filter design for harmonic reactive power compensation in single-phase circuits supplying nonlinear loads. IEE P-Gener Transm Distrib 147(6):373-380

[6] Akagi H (1994) Trend in active power line conditioners. IEEE Trans Power Electron 9(3):263-268

[7] Khadkikar V, Chandra A (2008) A new control philosophy for a unified power quality conditioner (UPQC) to coordinate loadreactive power demand between shunt and series inverters. IEEE Trans Power Deliv 23(4):2522-2534

[8] Luo A, Zhao W, Deng X et al (2009) Dividing frequency control of hybrid active power filter with multi-injection branches using improved $i_{p}-i_{q}$ algorithm. IEEE Trans Power Electron 24(10):2396-2405

[9] Zhao W (2010) Harmonic suppression and reactive power compensation theory and application research in high voltage distribution networks. Ph D Thesis, Hunan University, Changsha (in Chinese)

[10] Gyuyi L, Talor ER (1980) Characteristic of static, thyristorcontrolled shunt compensators for power transmission system applications. IEEE Trans Power Appar Syst 99(5):1795-1804

[11] Ghosh A, Ledwich G (2003) Load compensating DSTATCOM in weak AC systems. IEEE Trans Power Deliv 18(4):1302-1309

[12] Chan K, Kara A, Kieboom G (1998) Power quality improvement with solid state transfer switches. In: Proceedings of the 8th international conference on harmonics and quality of power, vol 1, Athens, 14-18 Oct 1998, pp 210-215

[13] Bashi SM, Jasni J, Weng OY (2003) Voltage regulation of uninterrupted power supplies. In: Proceedings of the IEEE student conference on research and development (SCOReD'03), Putrajaya, 25-26 Aug 2003, pp 385-389

[14] Liu JW, Choi SS, Chen S (2003) Design of step dynamic voltage regulator for power quality enhancement. IEEE Trans Power Deliv 18(4):1403-1409

[15] Fujita H, Akagi H (1998) The unified power quality conditioner: the integration of series and shunt-active filters. IEEE Trans Power Electron 13(2):315-322 
[16] Lesnicar A, Marquardt R (2003) An innovative modular multilevel converter topology suitable for a wide power range. In: Proceedings of the 2003 IEEE Bologna power technology conference, vol 3, Bologna, 23-26 June 2003, 6 pp

[17] Kouro S, Malinowski M, Gopakumar K et al (2010) Recent advances and industrial applications of multilevel converters. IEEE Trans Ind Electron 57(8):2553-2580

[18] Ghetti FT, Ferreira AA, Brage HAC, et al. (2012) A study of shunt active power filter based on modular multilevel converter (MMC). In: Proceedings of the 10th IEEE/IAS international conference on industry applications (INDUSCON'12), Fortaleza, 5-7 Nov 2012, 6 pp

[19] Nieves M, Maza JM, Mauricio JM, et al. (2014) Enhanced control strategy for MMC-based STATCOM for unbalanced load compensation. In: Proceedings of the 16th European conference on power electronics and applications (EPE'14-ECCE Europe), Lappeenranta, 26-28 Aug 2014, 10 pp

[20] Long YB, Xiao XN, Xu YH et al (2013) MMC-UPQC: application of modular multilevel converter on unified power quality conditioner. In: Proceedings of the 2013 IEEE Power and Energy Society general meeting (PES'13), Vancouver, 21-23 July 2013,5 pp

[21] Yao K, Ruan XB, Zou C et al (2012) Three-phase single-switch boost PFC converters with high input power factor. Proc CSEE 32(6):97-105 (in Chinese)

[22] Zeng Z, Zhao RX, Yang H et al (2012) A multi-functional gridconnected inverter and its application to customized power quality of microgrid. Power Syst Technol 36(5):58-67 (in Chinese)

[23] Leung CK, Dutta S, Baek S et al (2010) Design considerations of high voltage and high frequency three phase transformer for solid state transformer application. In: Proceedings of the 2010 IEEE energy conversion congress and exposition (ECCE'10), Atlanta, 12-16 Sept 2010, pp 1551-1558

[24] Railing RD, Moreau G, Ronström L et al (2004) Cross sound cable project second generation VSC technology for HVDC. In: Proceedings of the 2004 CIGRE conference, Paris, 21-23 July 2004, pp B4-B102

[25] Lam CS, Wong MC, Han YD (2012) Hysteresis current control of hybrid active power filters. IET Power Electron 5(7):1175-1187

[26] Suresh Y, Panda AK, Suresh M (2012) Real-time implementation of adaptive fuzzy hysteresis-band current control technique for shunt active power filters. IET Power Electron 5(7):1188-1195

[27] Kamran F, Habetler TG (1998) Combined deadbeat control of a series-parallel converter combination used as a universal power filter. IEEE Trans Power Electron 13(1):160-168

[28] Han Y, Xu L, Khan MM et al (2011) Robust deadbeat control scheme for a hybrid APF with resetting filter and ADELINEbased harmonic estimation algorithm. IEEE Trans Ind Electron 58(9):3893-3904

[29] Biagini V, Zanchetta P, Odavic M et al (2013) Control and modulation of a multilevel active filtering solution for variablespeed constant-frequency more-electric aircraft grids. IEEE Trans Ind Inform 9(2):600-608

[30] Drobni K, Nemec M, Nedeljkovic D et al (2009) Predictive direct control applied to AC drives and active power filter. IEEE Trans Ind Electron 56(6):1884-1893

[31] Acuña P, Morán L, Rivera $M$ et al (2015) A single-objective predictive control method for a multivariable single-phase threelevel NPC converter-based active power filter. IEEE Trans Ind Electron 62(7):4598-4607

[32] Panigrahi R, Subudhi B, Panda PC (2015) Model predictivebased shunt active power filter with a new reference current estimation strategy. IET Power Electron 8(2):221-233
[33] Xu Y, Li FX (2014) Adaptive PI control of STATCOM for voltage regulation. IEEE Trans Power Deliv 29(3):1002-1011

[34] Rahmani S, Mendalek N, Al-Haddad K (2010) Experimental design of a nonlinear control technique for three-phase shunt active power filter. IEEE Trans Ind Electron 57(10):3364-3375

[35] Micallef A, Apap M, Spiteri-Staines C et al (2014) Reactive power sharing and voltage harmonic distortion compensation of droop controlled single phase islanded microgrids. IEEE Trans Smart Grid 5(3):1149-1158

[36] Herman L, Papic I, Blazic B (2014) A proportional-resonant current controller for selective harmonic compensation in a hybrid active power filter. IEEE Trans Power Deliv 29(5):2055-2065

[37] Zou ZX, Zou KL, Wang Z et al (2015) Frequency-adaptive fractional-order repetitive control of shunt active power filters. IEEE Trans Ind Electron 62(3):1659-1668

[38] Grino R, Cardoner R, Costa-Castelló R et al (2007) Digital repetitive control of a three-phase four-wire shunt active filter. IEEE Trans Ind Electron 54(3):1495-1503

[39] Wu JY, Chen QC, Du MJ et al (2013) Sliding-mode variable structure controller for cascade static var compensator. IET Trans Power Electron 6(2):343-352

[40] Matas J, de Vicuña LG, Miret J et al (2008) Feedback linearization of a single-phase active power filter via sliding mode control. IEEE Trans Power Electron 23(1):116-125

[41] Al Chaer T, Gaubert JP, Rambault L et al (2009) Linear feedback control of a parallel active harmonic conditioner in power systems. IEEE Trans Power Electron 24(3):641-653

[42] Radzi MAM, Rahim NA (2009) Neural network and bandless hysteresis approach to control switched capacitor active power filter for reduction of harmonics. IEEE Trans Ind Electron 56(5):1477-1484

[43] Panigrahi R, Subudhi B, Panda PC (2016) A robust LQG servo control strategy of shunt- active power filter for power quality enhancement. IEEE Trans Power Electron 31(4):2860-2869

[44] He JW, Li YW, Blaabjerg F et al (2014) Active harmonic filtering using current-controlled, grid-connected DG units with closed-loop power control. IEEE Trans Power Electron 29(2):642-653

[45] Zobaa AF (2014) Optimal multiobjective design of hybrid active power filters considering a distorted environment. IEEE Trans Ind Electron 61(1):107-114

[46] Luo A, Shuai ZK, Zhu WJ et al (2012) Combined system for harmonic suppression and reactive power compensation. IEEE Trans Ind Electron 56(2):418-428

[47] Agorreta JL, Borrega M, López J et al (2011) Modeling and control of $N$-paralleled grid-connected inverters with LCL filter coupled due to grid impedance in PV plants. IEEE Trans Power Electron 26(3):770-785

[48] Xu W, Huang ZY, Cui Y et al (2005) Harmonic resonance mode analysis. IEEE Trans Power Deliv 20(2):1182-1190

[49] Xu DZ, Wang F, Mao HL et al (2013) Modeling and analysis of harmonic interaction between multiple grid-connected inverters and the utility grid. Proc CSEE 33(12):64-71 (in Chinese)

[50] Shuai ZK, Liu DG, Shen J et al (2014) Series and parallel resonance problem of wideband frequency harmonic and its elimination strategy. IEEE Trans Power Electron 29(4):1941-1952

[51] Shuai ZK, Xiao F, Tu CM et al (2013) Resonance degradation mechanism of wide-band frequency harmonics and elimination strategy. Trans China Electrotech Soc 28(12):16-23 (in Chinese)

[52] Zhong HQ, Xu ZX, Zou YP et al (2005) Effects of parasitical capacitors on charging characteristic of series resonant CCPS. Proc CSEE 25(10):40-44 (in Chinese)

[53] Luo A, Xie N, Shuai ZK (2015) Large-scale photovoltaic plant harmonic transmission model and analysis on resonance characteristics. IET Power Electron 8(4):565-573 
[54] Infield DG, Onions P, Simmons AD et al (2004) Power quality from multiple grid-connected single-phase inverters. IEEE Trans Power Deliv 19(4):1983-1989

[55] Indulkar CS, Viswanathan B, Venkata SS (1989) Maximum power transfer limited by voltage stability in series and shunt compensated schemes for AC transmission systems. IEEE Trans Power Deliv 4(2):1246-1252

[56] Ma FJ, Luo A, Shuai ZK et al (2014) Voltage ripple analysis of simplified active power compensator for negative sequence and reactive power compensation. IET Power Electron 7(10):2582-2594

[57] Luo A, Peng SJ, Wu CP et al (2012) Power electronic hybrid system for load balancing compensation and frequency-selective harmonic suppression. IEEE Trans Ind Electron 59(2):723-732

[58] Li YW, Nejabatkhah F (2014) Overview of control, integration and energy management of microgrids. J Mod Power Syst Clean Energy 2(3):212-222. doi:10.1007/s40565-014-0063-1

[59] Guerrero JM, De Vicuna LG, Matas J et al (2005) Output impedance design of parallel-connected UPS inverters with wireless load-sharing control. IEEE Trans Ind Electron 52(4):1126-1135

[60] Tuladhar A, Jin H, Unger T et al (2000) Control of parallel inverters in distributed AC power systems with consideration of line impedance effect. IEEE Trans Ind Appl 36(1):131-138

[61] Guerrero JM, De Vicuna LG, Matas J et al (2004) A wireless controller to enhance dynamic performance of parallel inverters in distributed generation systems. IEEE Trans Power Electron 19(5):1205-1213

[62] Ding GQ, Gao F, Zhang S, Loh PC, Blaabjerg F (2014) Control of hybrid AC/DC microgrid under islanding operational conditions. J Mod Power Syst Clean Energy 2(3):223-232. doi:10. 1007/s40565-014-0065-z

[63] Vasquez JC, Mastromauro RA, Guerrero JM et al (2009) Voltage support provided by a droop-controlled multifunctional inverter. IEEE Trans Ind Electron 56(11):4510-4519

[64] De Brabandere KD, Bolsens B, Van den Keybus J et al (2007) A voltage and frequency droop method for parallel inverters. IEEE Trans Power Electron 22(4):1107-1115

[65] Zhong QC (2013) Robust droop controller for accurate proportional load sharing among inverters operated in parallel. IEEE Trans Ind Electron 60(4):1281-1290

[66] Yao W, Chen M, Matas J et al (2011) Design and analysis of the droop control method for parallel inverters considering the impact of the complex impedance on the power sharing. IEEE Trans Ind Electron 58(2):576-588

[67] Guerrero JM, Vasquez JC, Matas J et al (2011) Hierarchical control of droop-controlled AC and DC microgrids: a general approach towards standardization. IEEE Trans Ind Electron 58(1):158-172

[68] Zhong QC, Zeng Y (2014) Control of inverters via a virtual capacitor to achieve capacitive output impedance. IEEE Trans Power Electron 29(10):5568-5578

[69] Chen YD, Guerrero JM, Shuai ZK et al (2015) Fast reactive power sharing, circulating current and resonance suppression for parallel inverters using resistive-capacitive output impedance. IEEE Trans Power Electron. doi:10.1109/TPEL.2015.2493103

[70] Wai RJ, Lin CY, Huang YC et al (2013) Design of high-performance stand-alone and grid-connected inverter for distributed generation applications. IEEE Trans Ind Electron 60(4):1542-1555

[71] Twining E, Holmes DG (2003) Grid current regulation of a three-phase voltage source inverter with an LCL input filter. IEEE Trans Power Electron 18(3):888-895

[72] Dannehl J, Fuchs FW, Hansen S et al (2010) Investigation of active damping approaches for PI-based current control of gridconnected pulse width modulation converters with LCL filters. IEEE Trans Ind Appl 46(4):1509-1517

[73] Shen GQ, Xu DH, Cao LP et al (2008) An improved control strategy for grid-connected voltage source inverters with an LCL filter. IEEE Trans Power Electron 23(4):1899-1906

[74] Malinowski M, Bernet S (2008) A simple voltage sensorless active damping scheme for three-phase PWM converters with an LCL filter. IEEE Trans Ind Electron 55(4):1876-1880

[75] Dannehl J, Liserre M, Fuchs FW (2011) Filter-based active damping of voltage source converters with LCL filter. IEEE Trans Ind Electron 58(8):3623-3633

[76] Wang F, Duarte JL, Hendrix MAM et al (2011) Modeling and analysis of grid harmonic distortion impact of aggregated DG inverters. IEEE Trans Power Electron 26(3):786-797

[77] Ghiani E, Pilo F (2015) Smart inverter operation in distribution networks with high penetration of photovoltaic systems. J Mod Power Syst Clean Energy 3(4):504-511. doi:10.1007/s40565015-0165-4

[78] Enslin JHR, Heskes PJM (2004) Harmonic interaction between a large number of distributed power inverters and the distribution network. IEEE Trans Power Electron 19(6):1586-1593

An LUO is a Professor with the College of Electrical and Information Engineering, Hunan University, where he also serves as the Chief of National Electric Power Conversion and Control Engineering Technology Research Center. He has published over 100 journal and conference articles. He is engaged in research on power conversion systems, harmonic suppression and reactive power compensation, and electric power saving.

Qianming XU received the B.S. degree from the College of Electrical and Information Engineering, Hunan University, in 2012. He has been working toward the Ph.D. degree in Hunan University since 2012. His research interests include multilevel converters, power quality control technique.

Fujun MA received the B.S. and Ph.D. degrees from Hunan University, Changsha, in 2008 and 2015, respectively. Since 2013, he has been an Assistant Professor with the College of Electrical and Information Engineering, Hunan University. His research interests include power quality managing technique of electrified railway, electric power saving, reactive power compensation, and active power filters.

Yandong CHEN received the Ph.D. degrees from Hunan University, Changsha, in 2014. Since 2014, he has been an Assistant Researcher with the College of Electrical and Information Engineering, Hunan University. His research interests include power electronics for Microgrid, distributed generation, and power quality. 